\title{
Comparison of DPC methods Using Two-Level and Three-Level Rectifiers
}

\author{
Jawad Lamterkati ${ }^{1}$, Mohamed Khafallah ${ }^{2}$, Lahcen Ouboubker ${ }^{3}$, Aziz Elafia ${ }^{4}$ \\ ${ }^{1,2,3}$ Hassan II University, Higher National School of Electricity and Mechanics (ENSEM), Casablanca 8118, Morocco \\ ${ }^{4}$ Hassan II University, Higher National School of Arts and trades (ENSAM), Casablanca, Morocco
}

\begin{abstract}
This paper contains the evaluation and comparison between DPC methods for two-level (2-L) and three-level (3-L) AC/DC converters, in order to demonstrate de great advantages of using a three level rectifier type NPC. The theoretical principal of this methods as well as the synthesis of the active and reactive power are discussed. The regulation of DC-bus voltage is achieved using PI controller. The effectiveness of this approach is shown by simulation results using Power System Bloc set (PSB) of Matlab/Simulink.
\end{abstract}

Keywords: Direct Power Control, two-level rectifier, three-level rectifier, instantaneous active and reactive power, switching table, corrector PI.

\section{Introduction}

In recent years, the trend of positively using PWM rectifier, as the dc power supplies for voltage-source inverters has been increasing $[1,3]$. The voltage-source PWM rectifierinverter has the following advantages: harmonics in inputoutput waveforms are fewer, input power factor can be controlled to be unity, generation is possible and the capacity of dc capacitor can be reduced etc.., the PWM rectifiers have more and more application such as active power filter (APF), unified power flow control (UPFC) and so on [1,2]. In the recent years, the research interest in three-phase PWM rectifiers is mainly influenced by the update of the control technology with the aim to: [3]

1)Ensure that the ac terminal current THD is less than $5 \%$ of the total fluctuation load to reduce the adverse effect on the grid.

2) Guarantee the power factor close to one and regard the rectifier as a ,pure resistive load" in terms of the grid;

3)Improve the dynamic characteristic for dc-bus voltage regulation, and reduce the dynamic response time, etc. [4, $5]$.

The high-performance control strategies of PWM rectifiers are mainly the voltage oriented control (VOC) [6] and direct power control (DPC) [7], which are similar to the vector control (VC) and direct torque control (DTC) [8] for AC machines. The VOC control scheme guarantees high dynamic and static performance via internal current control loops. However, the final configuration and performance of the VOC system largely depends on the quality of the applied current control strategy. With DPC there are not internal current control loops and no PWM modulator bloc, because the converter switching states are selected by a switching table based on the instantaneous errors between the commanded and estimated values of the active and reactive power, and voltage position vector. Therefore, the key point of the DPC implementation is a correct and fast estimation of the active and the reactive line power.

On the other hand, multi-level inverters have become a very attractive solution for high power application areas [9-10].
The three-level Neutral Point Clamped (NPC) inverter is one of the most commonly used multi-level inverter topologies in high power ac drives. By comparing to the standard twolevel inverter, the three-level inverter presents its superiority in terms of lower stress across the semiconductors, lower voltage distortion, less harmonic content and lower switching frequency [11].

The three level inverters present a big interest in the field of the high voltages and the high powers of the fact that they introduce less distortion and weak losses with relatively low switching frequency [12]. This paper presents a brief description and comparison of DPC methods of vector control using two and three-level $\mathrm{AC} / \mathrm{DC}$ converters, and to demonstrate the great advantages of using three level converters type NPC. The regulation dc-bus output is realized by corrector PI.

\section{DPC with Two Level Rectifier}

DPC block for PWM converter essentially comprises of active and reactive power comparators, power estimators and switching pattern generator. The DPC application in PWM converter is analogous to direct torque control (DTC) in inverter fed three-phase motor drives. Initially, DTC and DPC strategies had been implemented with look-up table based switching pattern generator.

\subsection{The principle and modeling of the two level rectifier}

The topology of three phase bidirectional voltage-source PWM rectifier (VSR) is shown in fig. 1. The VSR is connected to the three phase as source via smoothing $L$ and internal resistance $R$. The inductance act as a line filter for smoothing the line currents with minimum ripples. Insulated gate bipolar transistors (IGBTs) are used as the VSR power switches since IGBTs have features of high power rating, simple gate drives requirement and suitable for high frequency switching applications. It is assumed that a pure resistive load $R_{L}$ is connected at the dc-link capacitor $C$. [13] By assuming a balance three-phase and three wires system, the voltage equations of the PWM rectifier can be described by equation (1)-(3). 


\section{International Journal of Science and Research (IJSR) \\ ISSN (Online): 2319-7064}

Index Copernicus Value (2013): 6.14 | Impact Factor (2014): 5.611

$$
\begin{gathered}
{\left[\begin{array}{l}
e_{a} \\
e_{b} \\
e_{c}
\end{array}\right]=R\left[\begin{array}{l}
i_{a} \\
i_{b} \\
i_{c}
\end{array}\right]+L \frac{d}{d t}\left[\begin{array}{l}
i_{a} \\
i_{b} \\
i_{c}
\end{array}\right]+\left[\begin{array}{c}
v \\
v_{b} \\
v_{c}
\end{array}\right]} \\
C \frac{d V_{d c}}{d t}=S_{a} i_{a}+S_{b} i_{b}+S_{c} i_{c}-i_{d c}
\end{gathered}
$$

Where $S_{\mathrm{a}, \mathrm{b}, \mathrm{c}}$ is switching state of the converter. The phase voltages at the poles of the converter are equal to:

$$
\begin{aligned}
& v_{a}=\left(2 S_{a}-\left(S_{b}+S_{c}\right) / 3\right) \cdot V_{d c} \\
& v_{b}=\left(2 S_{b}-\left(S_{a}+S_{c}\right) / 3\right) \cdot V_{d c} \\
& v_{c}=\left(2 S_{c}-\left(S_{b}+S_{a}\right) / 3\right) \cdot V_{d c}
\end{aligned}
$$

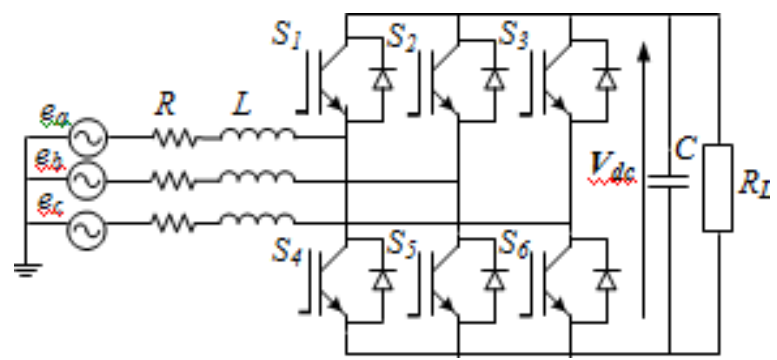

Figure 1: Configuration of three phase VSR

\subsection{Direct Power Control Strategy (2-Level)}

In this configuration, the dc-bus voltage is regulated by controlling the active power, and unity power factor operation is achieved by controlled the reactive power to be zero [13]. As shown in fig. 2, the active power command is provided from a dc-bus voltage control block, while the reactive power command is directly given from the outside of the controller. Errors between the commands and the estimated feedback power are input to the hysteresis comparators and digitized to the signals $S p$ and $S q$. Also, the phase of the power-source voltage vector is converted to the digitized signal $\theta_{n}$. For this purpose, the stationary coordinates are divided into 12 sectors, as shown in Fig. 3, and the sectors can be numerically expressed as:

$$
(n-2) \frac{\pi}{6} \leq \theta_{n} \leq(n-1) \frac{\pi}{6} \quad n=1,2, \ldots, 12
$$

By using several comparators, it is possible to specify the sector where the voltage vector exists.

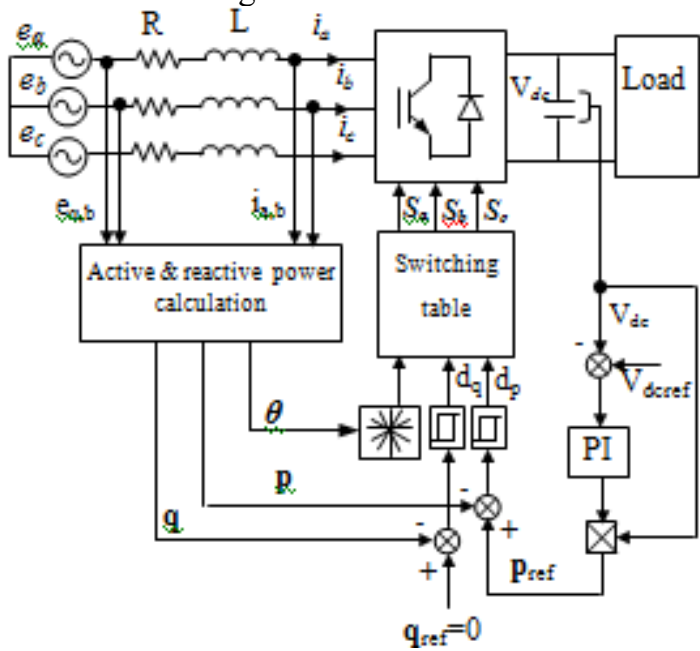

Figure 2: Configuration of direct instantaneous active and reactive power controller

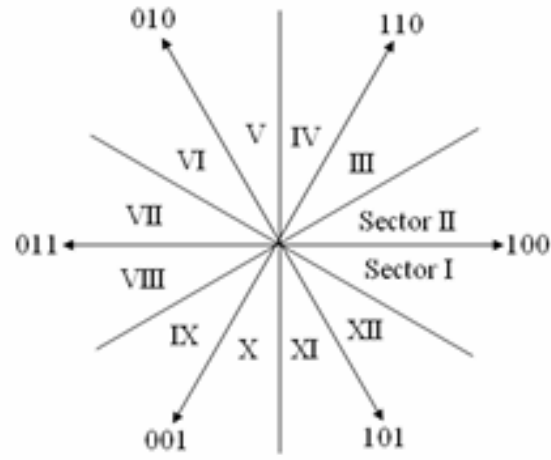

Figure 3: Twelve sector on stationary coordinates to specify voltage vector phase

It is known that the calculation of the active power $P$ is a scalar product between the voltages and the currents, whereas the reactive power $q$ can be calculated by a vector product between them [11]-[13].

$$
\begin{gathered}
p=v_{a} i_{a}+v_{b} i_{b}+v_{c} i_{c} \\
q=\frac{1}{\sqrt{3}}\left[\left(v_{b}-v_{c}\right) i_{a}+\left(v_{c}-v_{a}\right) i_{b}+\left(v_{a}-v_{b}\right) i_{c}\right]
\end{gathered}
$$

In terms of the switching states of the converter, the three phase line currents, the dc-bus voltage, and the inductance of the reactors, the estimated values of $p$ and $q$ and can be derived as:

$$
\begin{gathered}
\hat{p}=L\left(\frac{d i_{a}}{d t} i_{a}+\frac{d i_{b}}{d t} i_{b}+\frac{d i_{c}}{d t} i_{c}\right)+V_{d c}\left(S_{a} i_{a}+S_{b} i_{b}+S_{c} i_{c}\right) \\
\hat{q}=\sqrt{3} L\left(\frac{d i_{a}}{d t} i_{c}-\frac{d i_{c}}{d t} i_{a}\right) \\
-\frac{1}{\sqrt{3}} V_{d c}\left[\left(S_{a}\left(i_{b}-i_{c}\right)+S_{b}\left(i_{b}-i_{a}\right)+S_{c}\left(i_{a}-i_{b}\right)\right]\right.
\end{gathered}
$$

The digitized error signals and digitized voltage phase are input to the switching table in which every switching state $\mathrm{d} p$ and $\mathrm{d} q$ of the converter is stored, as shown in Table I.

By using this switching table, the optimum switching state of the converter can be selected uniquely in every specific moment according to the combination of the digitized input signals. The selection of the optimum switching state is performed so that the power errors can be restricted within the hysteresis bands.

Table 1: Conventional Switching Table For Direct Instantaneous Power Control

\begin{tabular}{|l|l|l|l|l|l|l|l|l|l|l|l|l|l|}
\hline$d_{g}$ & $d_{s}$ & $\theta_{l}$ & $\theta_{2}$ & $\theta_{3}$ & $\theta_{4}$ & $\theta_{5}$ & $\theta_{6}$ & $\theta_{7}$ & $\theta_{2}$ & $\theta_{9}$ & $\theta_{10}$ & $\theta_{I I}$ & $\theta_{I 2}$ \\
\hline 1 & 1 & 7 & 7 & 0 & 0 & 7 & 7 & 0 & 0 & 7 & 7 & 0 & 0 \\
\hline 1 & 0 & 6 & 7 & 1 & 0 & 2 & 7 & 0 & 3 & 7 & 4 & 0 & 5 \\
\hline 0 & 1 & 1 & 2 & 2 & 3 & 3 & 4 & 4 & 5 & 5 & 6 & 6 & 1 \\
\hline 0 & 0 & 6 & 1 & 1 & 2 & 2 & 3 & 3 & 4 & 4 & 5 & 5 & 6 \\
\hline
\end{tabular}




\section{International Journal of Science and Research (IJSR) \\ ISSN (Online): 2319-7064}

Index Copernicus Value (2013): 6.14 | Impact Factor (2014): 5.611

\section{DPC with Three Level Rectifier}

\subsection{Three-Level NPC Rectifier}

In the Neutral-Point Clamped inverter presented in fig. 4, the converter is built around twelve switching cells (based on IGBT, or others) and six clamp diodes; each phase can produce three distinct levels by connecting the output either to the positive $\left(\mathrm{V}_{\mathrm{dc}} / 2\right)$, negative $\left(-\mathrm{V}_{\mathrm{dc}} / 2\right)$ or null $(0)$ potential. In a three system it results in $3^{3}=27$ output voltage vectors, related to 19 possible voltage vectors at the output of the converter (fig. 5, and Table II).

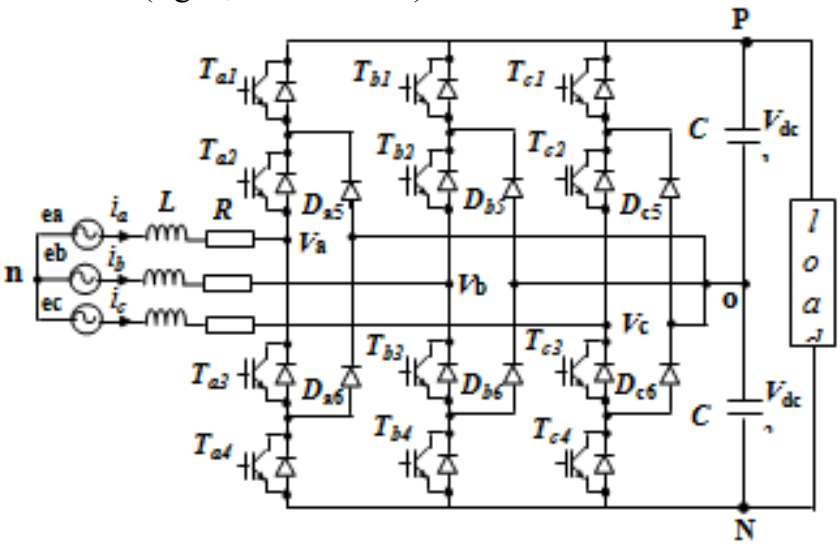

Figure 4: Schematic diagram of a three-level NPC rectifier

The output voltage space vector $\mathrm{V}_{\mathrm{i}}$ corresponding to the 19 different vectors can be classified into four categories according to its magnitude; it can be summarized in the Table II.

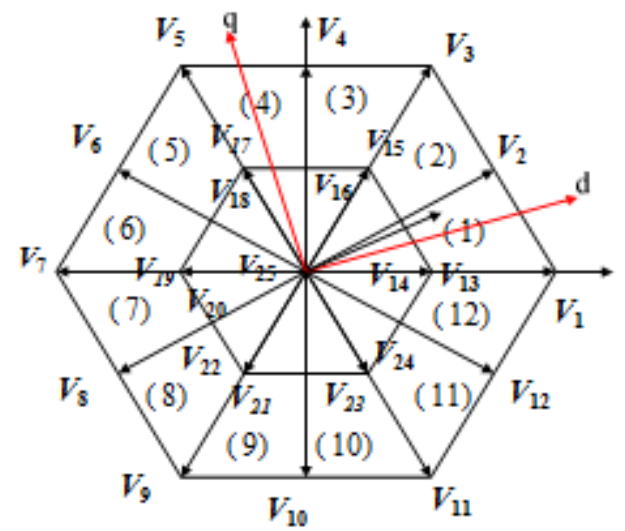

igure 5: Space vector diagram of three-level inverter.

Table 2: Voltage Space Vectors Generated By The Three-

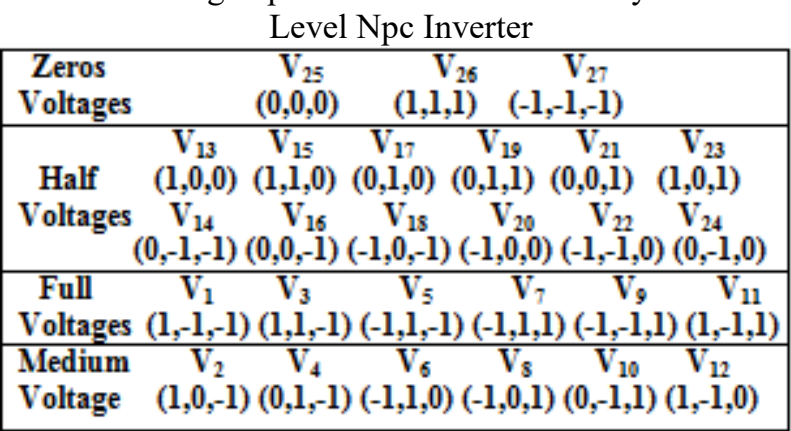

According to the defined switching functions, the state space equations can be developed in the three phase abc stationary coordinate system. In addition of the line currents, the dynamic of the capacitors is taken in to account and are selected as state variables. However, the phase voltage of the grid and the load current are considered as disturbances.

$$
\begin{aligned}
& L \frac{d i_{a}}{d t}=e_{a}-R i_{a}-S_{a 1} \cdot V_{d c 1}+S_{a 2} \cdot V_{c 2}-u_{o n} \\
& L \frac{d i_{b}}{d t}=e_{b}-R i_{b}-S_{b 1} \cdot V_{d c 1}+S_{b 2} \cdot V_{d c 2}-u_{o n} \\
& L \frac{d i_{c}}{d t}=e_{c}-R i_{c}-S_{c 1} \cdot V_{d c 1}+S_{c 2} \cdot V_{d c 2}-u_{o n} \\
& C_{d c 1} \frac{d v_{d c 1}}{d t}=S_{a 1} \cdot i_{a}+S_{b 1} \cdot i_{b}+S_{c 1} \cdot i_{c}-i_{L} \\
& C_{d c 2} \frac{d v_{d c 2}}{d t}=-S_{a 2} \cdot i_{a}-S_{b 2} \cdot i_{b}-S_{c 2} \cdot i_{c}-i_{L}
\end{aligned}
$$

Where $u_{x}$ and $i_{x}$ is the phase voltage and current of the grid $(\mathrm{x}=\mathrm{a}, \mathrm{b}, \mathrm{c}) . L$ and $R$ are the grid filter inductor and resistance, $\mathrm{V}_{\mathrm{dc}}$ is the dc voltage, and $\mathrm{I}_{\mathrm{L}}$ is the load current. [16][17] Considering the three-phase three-line grid system balanced.

$$
\begin{aligned}
& e_{a}+e_{b}+e_{c}=0 \\
& i_{a}+i_{b}+i_{c}=0
\end{aligned}
$$

The voltage $U_{\text {on }}$ can be done by:

$u_{o n}=-\frac{1}{3}\left(S_{a 1}+S_{b 1}+S_{c 1}\right) V_{d c 1}+\frac{1}{3}\left(S_{a 2}+S_{b 2}+S_{c 2}\right) V_{d c 2}$

\subsection{Direct Power Control Strategy (3-Level)}

Figure 6 is the block scheme of DPC for three-level PWM rectifier.

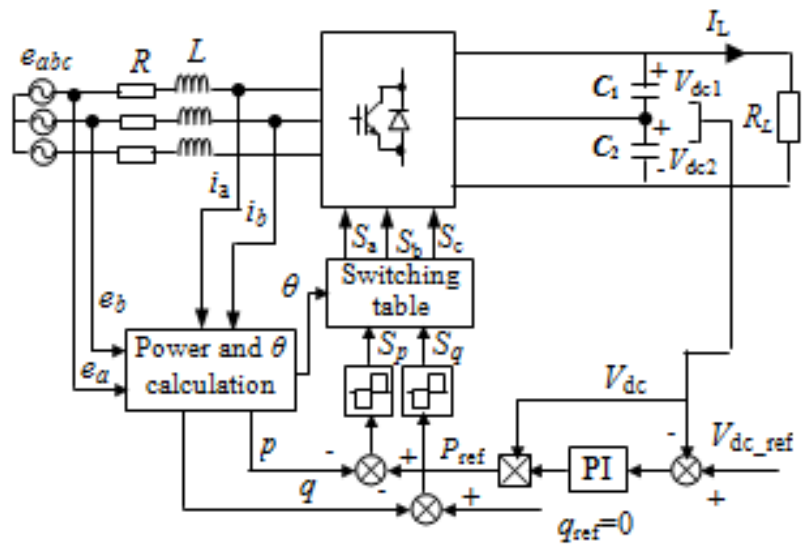

Figure 6: Block diagram of direct power control DPC

It is know that the mathematical model of three-level PWM rectifier in three-phase static abc coordinates as shown in (13):

$$
e_{j}=L \frac{d i_{j}}{d t}+R i_{j}+v_{j} \quad(j=a, b, c)(13)
$$

Where as:

$e_{j}, i_{j}$ : phase voltage and phase current of $j$-phase source. $v_{j}$ : the $\mathrm{j}$-phase neutral point voltage of rectifier in $\mathrm{AC}$ side.

According to coordinates transformation, and neglecting internal resistance of inductance, the mathematical model of three-level PWM rectifier in dq rotational coordinates is as: 


\section{International Journal of Science and Research (IJSR) \\ ISSN (Online): 2319-7064}

Index Copernicus Value (2013): 6.14 | Impact Factor (2014): 5.611

$$
\begin{aligned}
& L \frac{d i_{d}}{d t}=e_{d}-v_{d} \\
& L \frac{d i_{q}}{d t}=-v_{q}
\end{aligned}
$$

Where as:

$e_{d}, e_{q}$ : the d-axis and q-axis projections of source voltage, here $e_{d}$.

$\mathrm{i}_{\mathrm{d}}, \mathrm{i}_{\mathrm{q}}$ : the $\mathrm{d}$-axis and $\mathrm{q}$-axis projections of source current. $\mathrm{v}_{\mathrm{d}}, \mathrm{v}_{\mathrm{q}}$ : the $\mathrm{d}$-axis and q-axis projections of rectifier neutral point voltage in $\mathrm{AC}$ side.

According the instantaneous power theory:

$$
\begin{aligned}
& p=e_{d} i_{d}+e_{q} i_{q} \\
& q=e_{q} i_{d}-e_{d} i_{q}
\end{aligned}
$$

Where as:

$\mathrm{p}, \mathrm{q}$ : active and reactive power of source.

Equation (14) is multiplied by $e_{d}$, and equation (15) is substituted in to it. Then the mathematical model of threelevel PWM rectifier based on DPC in $d q$ rotational coordinates is described as:

$$
\begin{aligned}
& \frac{d p}{d t}=\frac{e_{d}}{L}\left(e_{d}-v_{d}\right) \\
& \frac{d q}{d t}=\frac{1}{L} e_{d} v_{q}
\end{aligned}
$$

It is evident that the active power and passive power could be controlled by the neutral point voltage of rectifier in $\mathrm{AC}$ side.

For example if the reference voltage vector was located in $\theta_{1}$, the influences of all space voltage vectors on active power and passive power were listed in Table. I. In Table.I, "+++"represents that the increment of active power or passive power is positive and the largest, "++" is the second, and "+" is less; "---"represents that the increment of active power or passive power is negative and its absolute value is the biggest, "--" is the second, and "-" is less; "0"represents that the increment of active power or passive power is zero. there is no influence of voltage vector on active or passive power. " $x$ "represents that the increment of active power or passive power is uncertain. It is evident that there are fewer voltage vectors to make active power decreased. When the reference voltage vector was located in the other sections, the similar result could be deduced. [18]

Table 3: The influence for active and reactive power of each switching vectors (sector 1 )

\begin{tabular}{|c|c|c|c|c|c|c|c|}
\hline Power & $\mathrm{V}_{0}$ & $\mathrm{~V}_{13}$ & $\mathrm{~V}_{14}$ & $\mathrm{~V}_{15}$ & $\mathrm{~V}_{16}$ & $\mathrm{~V}_{17}$ & $\mathrm{~V}_{18}$ \\
\hline $\mathrm{p}$ & ++ & + & + & ++ & ++ & ++ & + \\
\hline $\mathrm{q}$ & 0 & - & + & ++ & + & - & -- \\
\hline Power & $\mathrm{V}_{2}$ & $\mathrm{~V}_{4}$ & $\mathrm{~V}_{6}$ & $\mathrm{~V}_{8}$ & $\mathrm{~V}_{10}$ & $\mathrm{~V}_{12}$ & \\
\hline $\mathrm{p}$ & -- & + & ++ & ++ & ++ & $\mathrm{X}$ & \\
\hline $\mathrm{q}$ & + & ++ & ++ & - & -- & -- & \\
\hline Power & $\mathrm{V}_{1}$ & $\mathrm{~V}_{3}$ & $\mathrm{~V}_{5}$ & $\mathrm{~V}_{7}$ & $\mathrm{~V}_{9}$ & $\mathrm{~V}_{11}$ & \\
\hline $\mathrm{p}$ & --- & $\mathrm{X}$ & + & +++ & ++ & + & \\
\hline $\mathrm{q}$ & - & ++ & +++ & + & -- & --- & \\
\hline
\end{tabular}

\subsection{Switching table for three-Level rectifier}

From Table. 3, some conclusions can be carried out [19]. In each sector, there are only two switching vectors have the ability of decreasing the present active power. So it's not necessary to set two hysteresis comparators during the negative region of active power. Some switching vectors, such as $V_{3}$ and $V_{12}$, are indefinite influence to the active power. It's advisable to avoid selecting these vectors for fear uncontrollable states of the inverter. Then, the novel switching table is given in Table.4. Sp and Sq represent the demand of increment of active power and reactive power compared with reference value, which were decided by equation (17) and (18).

$$
\begin{aligned}
& \left\{\begin{array}{l}
\Delta p>H_{p 2} \rightarrow \mathrm{S}_{p}=2 \\
H_{p 2}>\Delta p>H_{p 1} \rightarrow \mathrm{S}_{P}=1 \\
H_{p 1}>\Delta p>-H_{p 1} \rightarrow \mathrm{S}_{P}=0 \\
\Delta p<-H_{p 1} \rightarrow \mathrm{S}_{p}=-1
\end{array}\right. \\
& \left\{\begin{array}{l}
\Delta q>H_{q} \rightarrow \mathrm{S}_{q}=1 \\
H_{q}>\Delta q>-H_{q} \rightarrow \mathrm{S}_{q}=0 \\
\Delta q<-H_{q} \rightarrow \mathrm{S}_{q}=-1
\end{array}\right.
\end{aligned}
$$

\begin{tabular}{|c|c|c|c|c|c|c|c|c|c|c|c|c|c|}
\hline & $\mathrm{S}_{\mathrm{q}}$ & $\theta_{1}$ & $\theta_{2}$ & $\theta_{3}$ & $\theta_{4}$ & $\theta_{5}$ & $\theta_{6}$ & $\theta_{7}$ & $\theta_{8}$ & $\theta_{9}$ & $\theta_{10}$ & $\theta_{11}$ & $\theta_{12}$ \\
\hline \multirow{3}{*}{2} & 1 & $V_{5}$ & $\mathrm{~V}_{6}$ & $V_{7}$ & $\mathrm{~V}_{8}$ & $\mathrm{~V}_{9}$ & $\mathrm{~V}_{10}$ & $\mathrm{~V}_{11}$ & $V_{12}$ & $\mathrm{~V}_{1}$ & $\mathrm{~V}_{2}$ & $\mathrm{~V}_{3}$ & $\mathrm{~V}_{4}$ \\
\hline & 0 & $\mathrm{~V}_{7}$ & $\mathrm{~V}_{8}$ & $\mathrm{~V}_{9}$ & $\mathrm{~V}_{10}$ & $\mathrm{~V}_{11}$ & $\mathrm{~V}_{12}$ & $\mathrm{~V}_{1}$ & $\mathrm{~V}_{2}$ & $\mathrm{~V}_{3}$ & $\mathrm{~V}_{4}$ & $\mathrm{~V}_{5}$ & $\mathrm{~V}_{6}$ \\
\hline & -1 & $\mathrm{~V}_{8}$ & $\mathrm{~V}_{9}$ & $V_{10}$ & $\mathrm{~V}_{11}$ & $V_{12}$ & $\mathrm{~V}_{1}$ & $\mathrm{~V}_{2}$ & $\mathrm{~V}_{3}$ & $\mathrm{~V}_{4}$ & $\mathrm{~V}_{5}$ & $\mathrm{~V}_{6}$ & $\mathrm{~V}_{7}$ \\
\hline \multirow{3}{*}{ 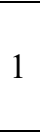 } & 1 & $\mathrm{~V}_{17}$ & $\mathrm{~V}_{17}$ & $\mathrm{~V}_{19}$ & $\mathrm{~V}_{19}$ & $\mathrm{~V}_{21}$ & $\mathrm{~V}_{21}$ & $V_{23}$ & $V_{23}$ & $\mathrm{~V}_{13}$ & $\mathrm{~V}_{13}$ & $\mathrm{~V}_{15}$ & $\mathrm{~V}_{15}$ \\
\hline & 0 & $V_{25}$ & $\mathrm{~V}_{25}$ & $V_{26}$ & $V_{26}$ & $\mathrm{~V}_{25}$ & $\mathrm{~V}_{25}$ & $\mathrm{~V}_{26}$ & $\mathrm{~V}_{26}$ & $\mathrm{~V}_{25}$ & $\mathrm{~V}_{25}$ & $\mathrm{~V}_{26}$ & $\mathrm{~V}_{26}$ \\
\hline & \begin{tabular}{|l|}
-1 \\
\end{tabular} & $V_{21}$ & $\mathrm{~V}_{21}$ & $V_{23}$ & $V_{23}$ & $V_{13}$ & $\mathrm{~V}_{13}$ & $\mathrm{~V}_{15}$ & $V_{15}$ & $\mathrm{~V}_{17}$ & $\mathrm{~V}_{17}$ & $\mathrm{~V}_{19}$ & $\mathrm{~V}_{19}$ \\
\hline \multirow{3}{*}{0} & 1 & $\mathrm{~V}_{2}$ & $V_{3}$ & $\mathrm{~V}_{4}$ & $\mathrm{~V}_{5}$ & $\mathrm{~V}_{6}$ & $\mathrm{~V}_{7}$ & $\mathrm{~V}_{8}$ & $\mathrm{~V}_{9}$ & $\mathrm{~V}_{10}$ & $\mathrm{~V}_{11}$ & $V_{12}$ & $\mathrm{~V}_{1}$ \\
\hline & 0 & $\mathrm{~V}_{13}$ & $\mathrm{~V}_{13}$ & $\mathrm{~V}_{15}$ & $\mathrm{~V}_{15}$ & $\mathrm{~V}_{17}$ & $\mathrm{~V}_{17}$ & $\mathrm{~V}_{19}$ & $V_{19}$ & $\mathrm{~V}_{21}$ & $\mathrm{~V}_{21}$ & $V_{23}$ & $\mathrm{~V}_{23}$ \\
\hline & -1 & $\mathrm{~V}_{11}$ & $\mathrm{~V}_{12}$ & $\mathrm{~V}_{1}$ & $\mathrm{~V}_{2}$ & $\mathrm{~V}_{3}$ & $\mathrm{~V}_{4}$ & $V_{5}$ & $\mathrm{~V}_{6}$ & $\mathrm{~V}_{7}$ & $\mathrm{~V}_{8}$ & $\mathrm{~V}_{9}$ & $\mathrm{~V}_{10}$ \\
\hline & 1 & $\mathrm{~V}_{1}$ & $\mathrm{~V}_{1}$ & $V_{3}$ & $V_{3}$ & $V_{5}$ & $\mathrm{~V}_{5}$ & $\mathrm{~V}_{7}$ & $\mathrm{~V}_{7}$ & $\mathrm{~V}_{9}$ & $\mathrm{~V}_{9}$ & $\mathrm{~V}_{11}$ & $\mathrm{~V}_{11}$ \\
\hline & 0 & $V_{1}$ & $\mathrm{~V}_{1}$ & $\mathrm{~V}_{3}$ & $V_{3}$ & $V_{5}$ & $\mathrm{~V}_{5}$ & $\mathrm{~V}_{7}$ & $\mathrm{~V}_{7}$ & $\mathrm{~V}_{9}$ & $\mathrm{~V}_{9}$ & $\mathrm{~V}_{11}$ & $\mathrm{~V}_{11}$ \\
\hline & -1 & $V_{12}$ & $V_{12}$ & $V_{2}$ & $\mathrm{~V}_{2}$ & $\mathrm{~V}_{4}$ & $\mathrm{~V}_{4}$ & $\mathrm{~V}_{6}$ & $\mathrm{~V}_{6}$ & $\mathrm{~V}_{8}$ & $\mathrm{~V}_{8}$ & $V_{10}$ & \\
\hline
\end{tabular}

Where, $\mathrm{H}_{\mathrm{p} 1}, \mathrm{H}_{\mathrm{p} 2}$ and $\mathrm{H}_{\mathrm{q}}$ are hysteresis bands of active and reactive power comparators; $\Delta \mathrm{p}$ and $\Delta \mathrm{q}$ is the error between the commands and the estimated feedback power.

Table 4: Switching table of DPC for three-level PWM rectifier

\section{Simulation result}

To study the effectiveness of the DPC with three-level PWM rectifier, it is implemented in Matlab/Simulink environment using power system bloc-set (PSB). The simulation results obtained for different condition show that:

- The dc link voltage variation, when step change applied to $\mathrm{V}_{\text {dcref }}$ (from 600 to 700 volt) figure.7(a) for a DPC twolevel rectifier and figure.7( $\left.\mathrm{a}^{\mathrm{ec}}\right)$ for a DPC three-level rectifier.

- Figure. 7(b) show the active and reactive power in AC line side with the DPC two-level rectifier scheme when the 


\section{International Journal of Science and Research (IJSR) \\ ISSN (Online): 2319-7064 \\ Index Copernicus Value (2013): 6.14 | Impact Factor (2014): 5.611}

step is applied, from this response it is observed that the ripple in the active power response is around 4.5 and $6.2 \mathrm{kw}$. Figure. $8\left(\mathrm{~b}^{\mathrm{c}}\right)$ show the active power with the DPC three-level rectifier, here the ripple is around 4.6 and $6.25 \mathrm{kw}$. This results show that the active power in threelevel scheme has been reduced significantly. To obtain a unity power factor in $\mathrm{AC}$ line side the input reference of reactive power is set to zero and active power change, so the dc voltage is regulated at set point value.

- Line current obtained by DPC three-level (figure. 8( $\left.\mathrm{c}^{\mathrm{e}}\right)$ ) is quasi-sinusoidal. However, there are lower ripple in line current thane hose in DPC two-level. Moreover, as shown in FFT analysis diagrams, the THD of line current in DPC three-level is $3.48 \%$ (figure.8 (d)), which is much lower than that $4.90 \%$ in DPC two-level (figure.7 (d)).

- Line current and voltage is shown in (figure7. (e) for a DPC two-level and figure.8 ( $\mathrm{e}^{\mathrm{e}}$ ) for a DPC three-level rectifier). As shown in this figures the line current has some phase respect to line voltage.
The performances of the DPC two-level and the DPC threelevel against the load disturbance under unit power factor operation. At $0.5 \mathrm{~s}$, the load power of each system has been increased $100 \%$. It can be observed that both methods maintain UPF successfully and keep DC-bus voltage close to the reference value (figure.7 (f) for a DPC two-level and figure. 8 ( $\mathrm{f}^{\mathrm{e}}$ ) for a three-level rectifier). In these figures the change in the load don't affect DC link voltage and only change the amplitude of the line current (figure.7 (g) for a DPC two-level and figure. 8 ( $\mathrm{g}^{\mathrm{ec}}$ ) for a three-level rectifier) and the line active side active power (figure.7 (h) for a DPC two-level and figure. 8 ( $h^{\text {eq }}$ ) for a three-level rectifier).

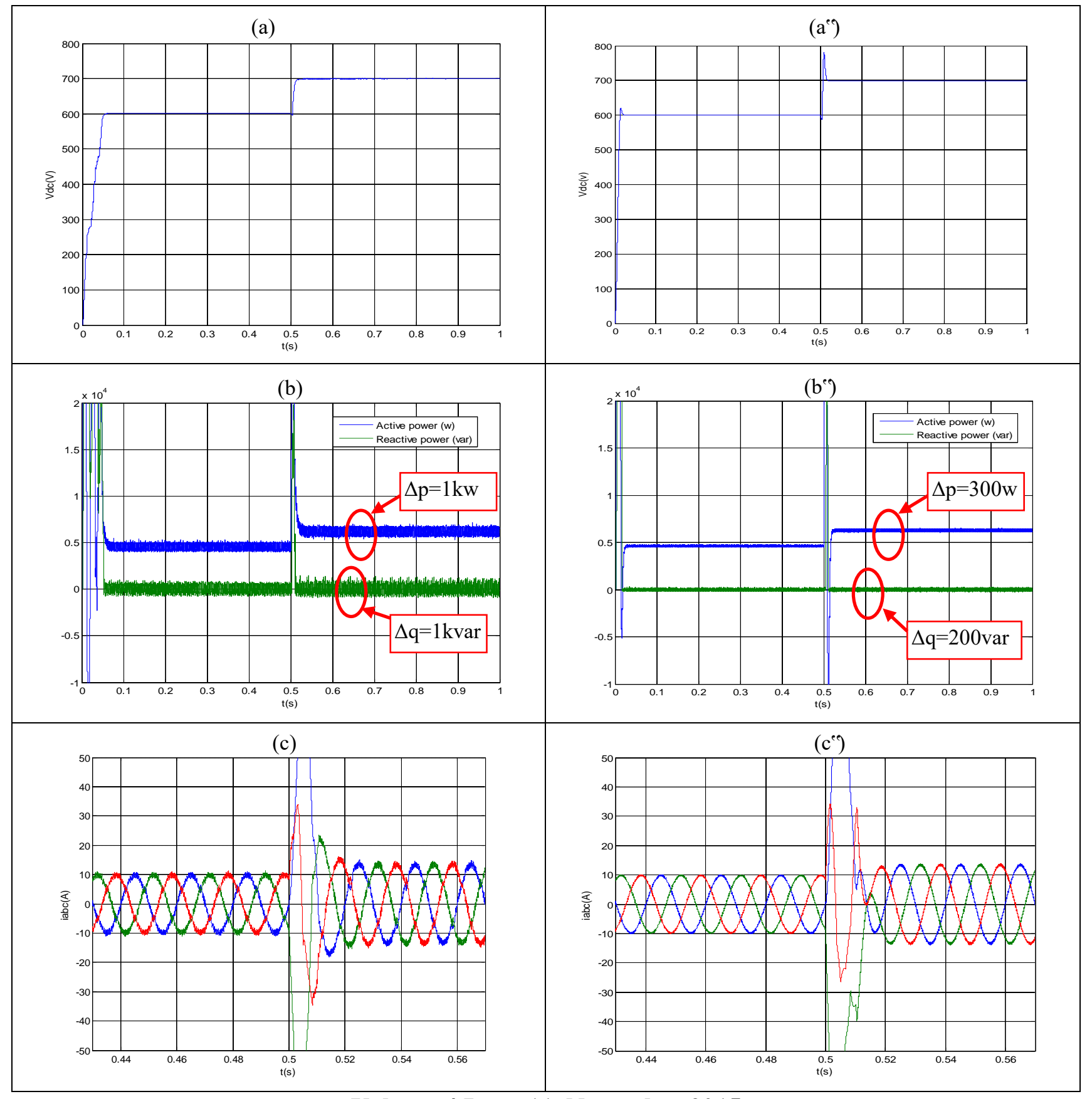

Volume 4 Issue 11, November 2015 
International Journal of Science and Research (IJSR)

ISSN (Online): 2319-7064

Index Copernicus Value (2013): 6.14 | Impact Factor (2014): 5.611

(d)

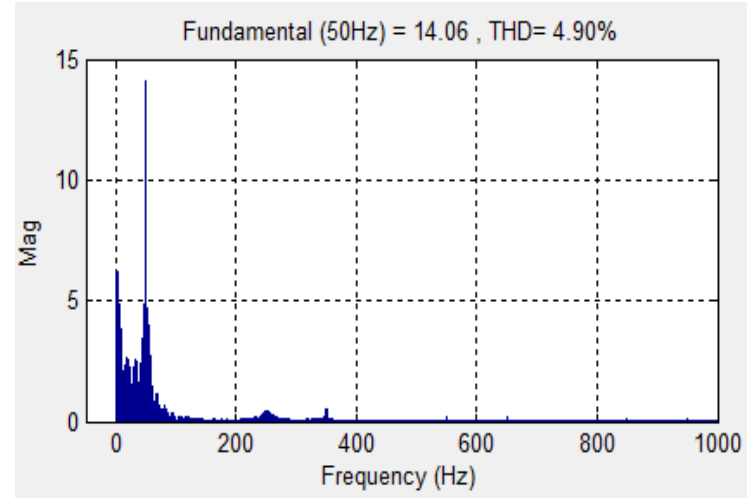

(d")

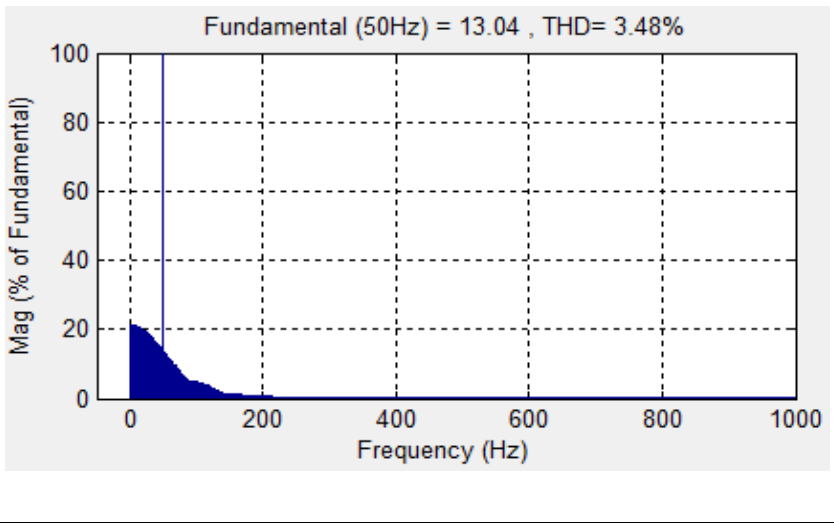

(e)

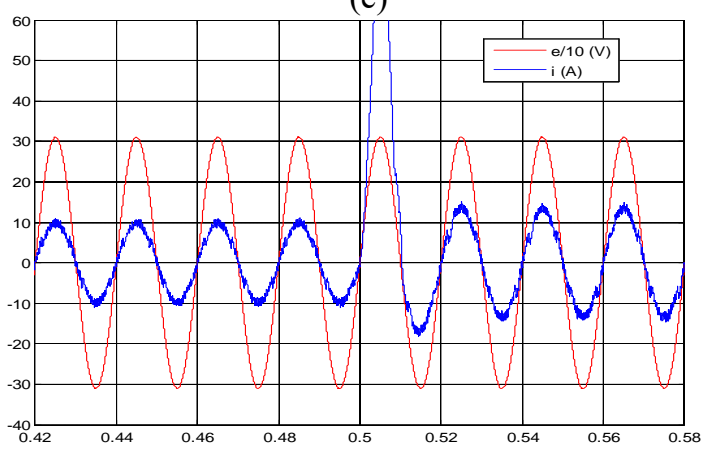

(f)

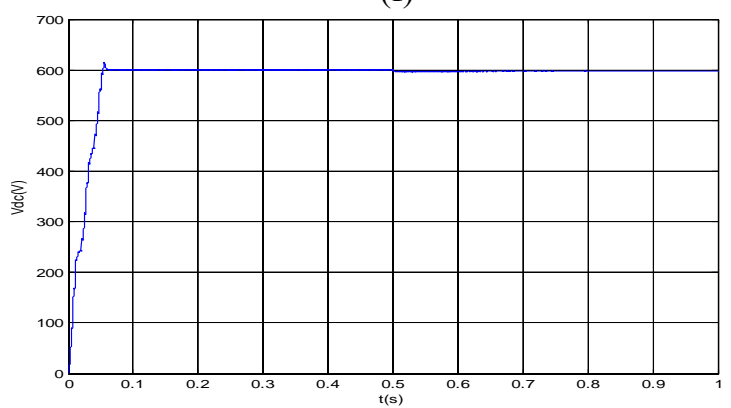

(g)

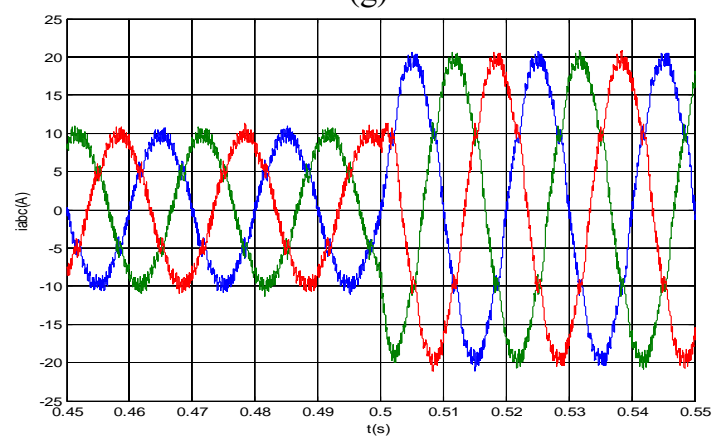

$\left(e^{e}\right)$

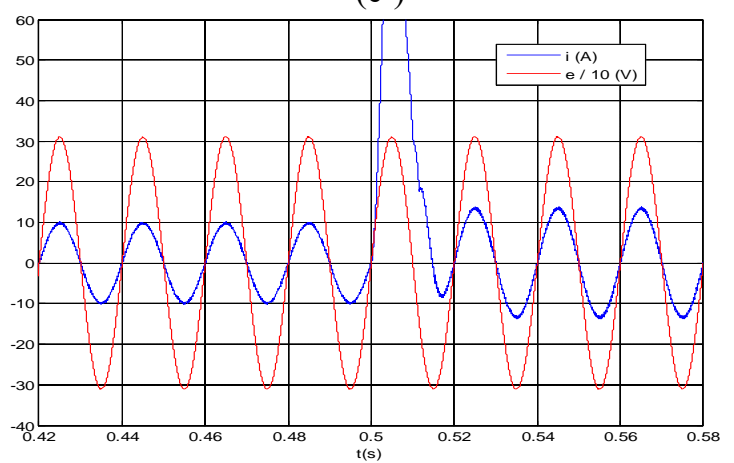

$\left(f^{\prime \prime}\right)$

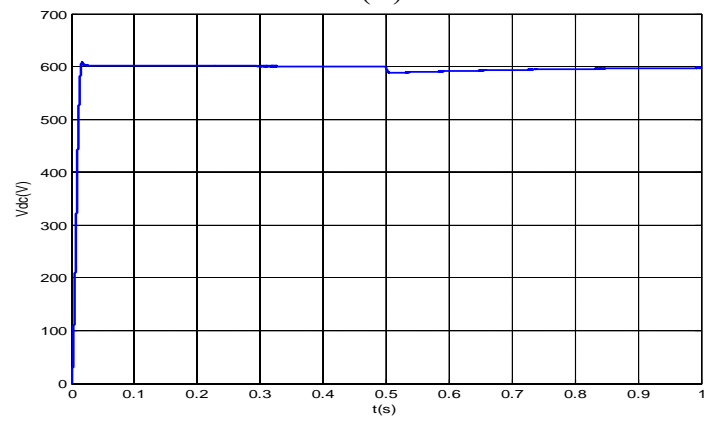

( $\left.g^{\prime \prime}\right)$

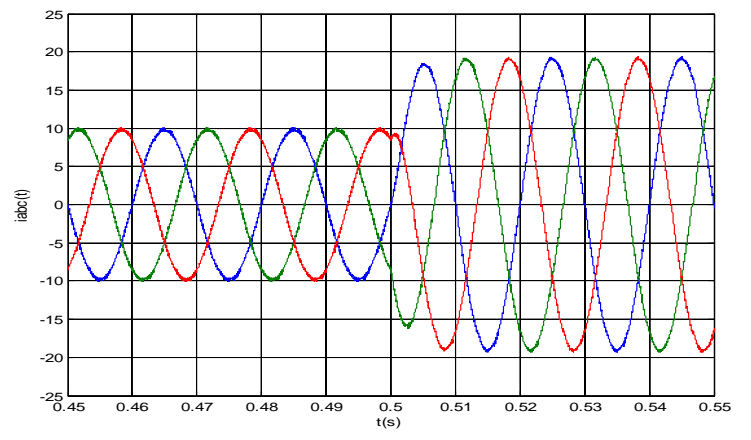

Volume 4 Issue 11, November 2015 


\section{International Journal of Science and Research (IJSR)

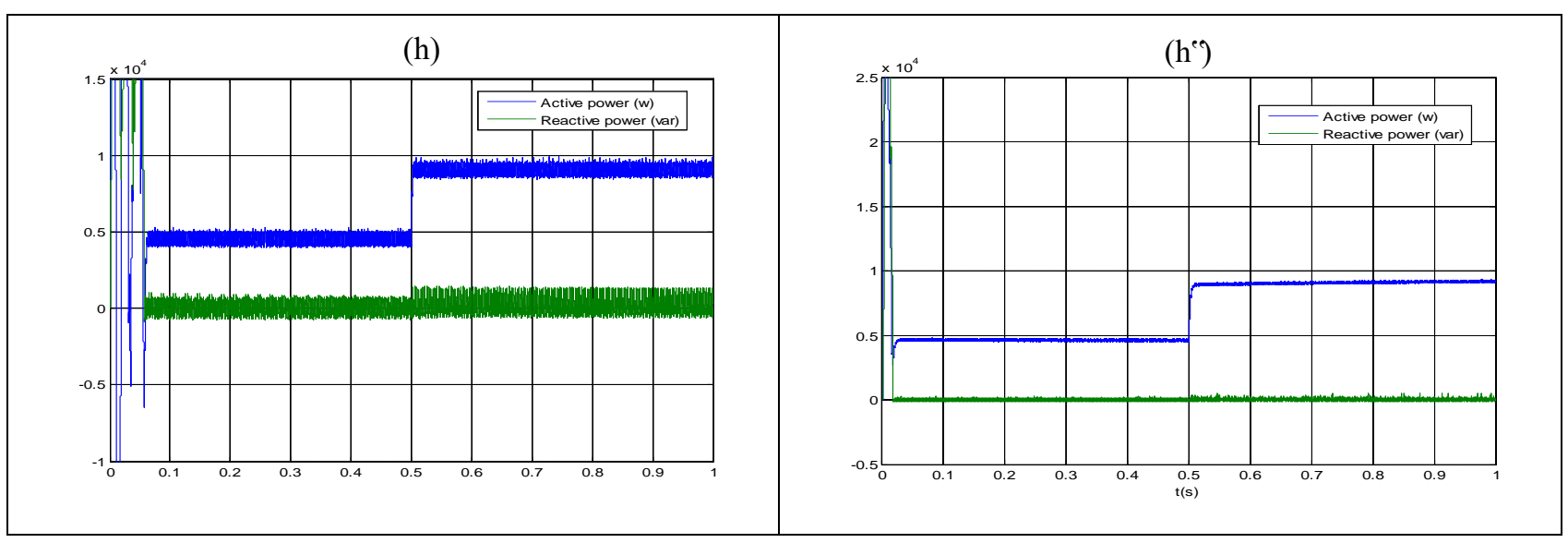

Table 5 : Parameters of circuit

\begin{tabular}{|c|c|}
\hline Parameters & Value \\
\hline Line voltage $(e)$ & $220 \mathrm{~V}$ \\
\hline Line frequency $(f)$ & $50 \mathrm{~Hz}$ \\
\hline DC bus voltage $\left(V_{d c r e f}\right)$ & $600 \mathrm{~V}$ \\
\hline Line resistance $(R)$ & $0.25 \Omega$ \\
\hline Line Inductance $(L)$ & $10 \mathrm{mH}$ \\
\hline DC link capacitor $(C)$ & $2000 \mu \mathrm{F}$ \\
\hline Sampling time $\left(T_{s}\right)$ & $5 \mu \mathrm{s}$ \\
\hline
\end{tabular}

\section{Conclusion}

In this article we present a DPC control strategy for twolevel and three-level PWM rectifier. To predict behavior of DPC of three phase PWM rectifier in different load and supply conditions, dynamic model is implemented in SIMULINK/MATLAB.

The main goal of the control system is to maintain the DCbus voltage at the required value and achieve UPF operation. The DPC using three-level PWM rectifiers presents good performance and ripples reductions, compared with conventional DPC. In this case, some techniques were developed in order to replace the DPC using two-level rectifiers switching table adapted for NPC rectifier.

\section{References}

[1] Hu, J. B., H. Nian, B. Hu, Y. K. He \& Z. Q. Zhu, "Direct Active and Reactive Power Regulation of DFIG Using Sliding-Mode Control Approach." IEEE Transactions on Energy Conversion, vol. 25, pp. 10281039, Dec 2010.

[2] Monteiro J., Silva J.F., Pinto S.F., Palm, J., "Direct power control of matrix converter based unifier power flow controllers." Industrial Electronics,2009, IECON ${ }^{\mathrm{e}} 09$, 35th Annual Conference of IEEE, 2006,pp.1525-1530

[3] Vazquez, S., J. A. Sanchez, J. M. Carrasco, J. I. Leon \& E. Galvan, "A model-based direct power control for three-phase power converters" IEEE Transactions on Industrial Electronics, vol. 55, pp. 1647-1657,Apr 2008.

[4] J. Huang, A. Zhang, H. Zhang, J. Wang, “A Novel Fuzzy-Based and Voltage-Oriented Direct Power Control Strategy for Rectifier”, IEEE Conf., 2011.
[5] Hu, J.B., et al., "Direct Active and Reactive Power Regulation of Grid-Connected DC/AC Converters Using Sliding Mode Control Approach." IEEE Transactions on Power Electronics, 2011. 26(1): p.210222.

[6] W. S. Song, X. Y. Feng, and C. L. Xiong, "a neutral point voltage regulation method with SVPWM control for single-phase three-level NPC converters," IEEE Vehicle Power and Propulsion Conference, pp. 1-4, 2008.

[7] N. Li, Y. Wang, S. Li, Y. F. Li, and Z. A. Wang, "Direct power control strategy used in three-level NPC converters",International Power Electronics and Motion Control Conference, pp. 1675-1679, 2012.

[8] C. Ortega, A. Arias, C. Caruana, J. Balcells, and G. Asher, "Improved waveform quality in the direct torque control of matrix-converter-fed PMSM drives," IEEE Trans. Ind. Electron., Vol. 57, No. 6, pp. 21012110, Jun. 2010

[9] J. Rodriguez, S. Bernet, B. Wu, J. O. Pontt, S. Kouro, "Multilevel voltage-source-converter topologies for industrial medium-voltage drives", IEEE Transactions on Industrial Electronics, Vol. 54, No. 6, pp.29302945, 2007.

[10] Y. Zhang, Z. Zhao, "Study on capacitor voltage balance for multilevelinverter based on a fast SVM algorithm", Proceeding of the CSEE(in Chinese), Vol. 26, No. 18, pp. 71-76, 2006.

[11] L. Dalessandro, S. D. Round, J. W. Kolar, "Centerpoint voltage balancing of hysteresis current controlled three-level PWM rectifiers", IEEE Transactions on Power Electronics, Vol. 23, No. 5, pp. 2477-2488, 2008.

[12] L.Ouboubker, M.Khafallah, J.Lamterkati, K.Chikh, "Comparison between DTC using a two-level inverters and DTC using a three level inverters of Induction Motor ", Multimedia Computing and Systems (ICMCS), 2014 International Conference, pp. 10511058, April 2014.

[13] T. Noguchi, H. Tomiki, S. Kondo, I. Takahashi ”Direct Power Control of PWM Converter Without PowerSource Voltage Sensors" IEEE Transaction on Industry Applications, Vol. 34, No. 3, May/June 1998, pp. 473 479.

[14] E. H. Watanabe, R. M. Stephan, and M. Aredes, New concepts of instantaneous active and reactive powers in 
electrical systems with generic loads, IEEE Trans Power delivry, vol. 8, pp. 697- 703, April 1993.

[15] T. Furuhoshi, S. Okuma, and Y. Uchikawa, A study on the theory of instantaneous reactive power, IEEE Trans Ind electron, vol. 37, pp. 86-90, February 1990.

[16] Wei Chen; Yunping Zou; Lijuan Xu; "Direct power control for Neutral-point-clamped three-level PWM rectifier". IEEE international conference on industrial technology, Chengdu. IEEE ICIT 2008, pp. 1-6,21-24 April 2008.

[17] G. Escobar, J. Leyva-Ramos, J.M, Carrasco, E. Galvan, R.C. Portillo, M.M. Prats, L.G, Franquelo; "Modeling of a three level converter used in a synchronous rectifier application". Power Electronics Specialists Conference, PESC 04, pp. 4306 - 4311 Vol.6, IEEE 35th Annual 20-25 June 2004.

[18] WU Wenjun, ZHONG Yanru, and WANG Jianjun; "The comparative Study of Different Methods about Constructing Switching Table in DPC for Three-level Rectifier". Power Electronics for Distributed Generation Systems (PEDG), 2nd IEEE International Symposium 2010.

[19] Lie Xu, Dawei Zhi, Liangzhong Yao. Direct Power Control of Grid Connected Voltage Source Converters. IEEE-PES Conf., Jun. 2007, pp. 1- 6.

\section{Author Profile}

Jawad Lamterkati: was born in morocco in 1980 . He received the Bachelor"s and Master"s degrees in electrical engineering from the Faculty of Science and Technology in 2005 and the Faculty of Science Semlalia in 2007, Marrakech, Morocco, respectively. He prepares, currently, a Doctorate Thesis in Electrical Engineering, Department at the National Higher School of Electricity and Mechanics (ENSEM), Hassan II University, Casablanca, Morocco.

Mohamed Khafallah: was born in Morocco in 1964 He received B.Sc., M.Sc. and Doctorate Degrees from Hassan II University, Casablanca, in 1989, 1991 and 1995 respectively, all in Electrical Engineering. In 1995 he joined the Department of Electrical Engineering at the National Higher School of Electricity and Mechanics (ENSEM), Hassan II University, Casablanca. His current Research interests are in the application of Power Electronics Converts and Motor Drive.

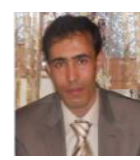

Lahcen Ouboubker: was born in morocco in 1983. $\mathrm{He}$ received the Bachelor ${ }^{\text {ec }} \mathrm{s}$ and Master"s degrees in electrical engineering from the Faculty of Science Semlalia in 2005 and 2007, Marrakech, Morocco, respectively. He prepares, currently, a Doctorate Thesis in Electrical Engineering, Department at the National Higher School of Electricity and Mechanics (ENSEM), Hassan II University, Casablanca, Morocco.

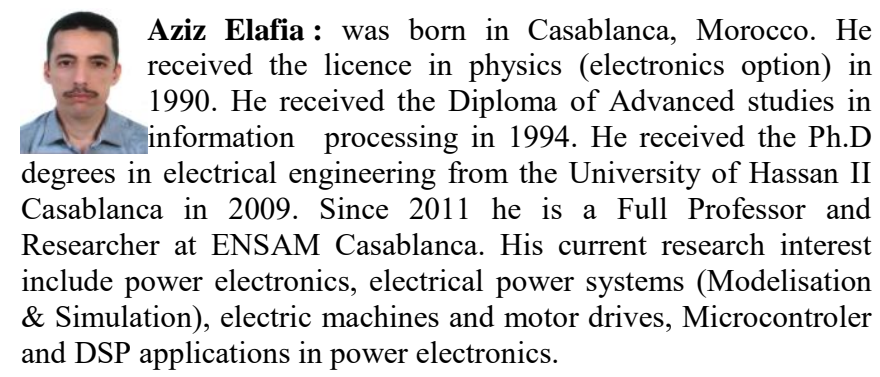

Volume 4 Issue 11, November 2015 www.ijsr.net 